\title{
PLEOMORPHIC ADENOMA LEADING TO ANATOMICAL DIVISION OF THE PAROTID GLAND
}

\author{
Naresh V. Dawat ${ }^{1}$, Pooja Sancheti², Haritosh K. Velankar ${ }^{3}$, Sharad B. Bhalekar ${ }^{4}$, Akanksha Saberwal ${ }^{5}$
}

${ }^{1}$ Post Graduate Student, Department of ENT, Dr. D. Y. Patil Hospital and Research Centre. ${ }_{2}^{2}$ Post Graduate Student, Department of ENT, Dr. D. Y. Patil Hospital and Research Centre. 3 Professor and HOD, Department of ENT, Dr. D. Y. Patil Hospital and Research Centre. ${ }^{4}$ Associate Professor, Department of ENT, Dr. D. Y. Patil Hospital and Research Centre. ${ }^{5}$ Assistant Professor, Department of ENT, Dr. D. Y. Patil Hospital and Research Centre.

ABSTRACT: The parotid glands are paired salivary glands situated on either side of the face, between ear and ramus of mandible. The main trunk of facial nerve enters the posterior surface of the gland and quickly bifurcates into upper and lower divisions, which arbitrarily define the superficial and deep lobes of the parotid gland. There is no histological demarcation between these two lobes. We hereby present a case of a tumor that pathologically lead to anatomical division of the parotid gland.

KEYWORDS: Parotid, Facial, Nerve, Superficial, Adenoma.

HOW TO CITE THIS ARTICLE: Naresh V. Dawat, Pooja Sancheti, Haritosh K. Velankar, Sharad B. Bhalekar, Akanksha Saberwal. "Pleomorphic Adenoma leading to anatomical division of the parotid gland." Journal of Evolution of Medical and Dental Sciences 2015; Vol. 4, Issue 93, November 19; Page: 15905-15907, D0I: 10.14260/jemds/2015/2313.

INTRODUCTION: Salivary gland tumors are relatively rare with an overall incidence of between 2.5 and 3.0 per $1,00,000$ per year. About 80 percent are benign. Salivary malignancies account for around 5 percent of malignancies of the head and neck. ${ }^{1,2}$ Approximately, 70 to 90 percent of salivary tumors are located in the parotid region.1,2,3 Pleomorphic adenoma comprises of 60 to 80 percent of parotid neoplasms.

Pleomorphic adenoma is a common benign salivary gland neoplasm characterised by neoplastic proliferation of parenchymatous glandular cells along with myoepithelial components, having a malignant potentiality. It is the most common type of salivary gland tumor and the most common tumor of the parotid gland.

It derives its name from the architectural pleomorphism (Variable appearance) seen by light microscopy. It is also known as "Mixed tumor, salivary gland type," which describes its pleomorphic appearance as opposed to its dual origin from epithelial and myoepithelial elements.

It occurs in patients of all ages with the highest incidence noted in the fourth to fifth decades. Both sexes are equally affected. Of those arising in the parotid gland, 80 percent are located in the superficial lobe in the tail of the gland; however, they are also seen in the deep lobe, the preauricular area, and anteriorly over the masseter muscle.

Parotid pleomorphic adenomas usually present as slow growing, painless tumors. Facial nerve palsy is never seen in benign cases. However, if left untreated, up to 5 percent may become malignant (Carcinoma ex pleomorphic adenomas). For, this reason surgical excision is always advised.

Financial or Other, Competing Interest: None.

Submission 27-10-2015, Peer Review 28-10-2015,

Acceptance 09-11-2015, Published 19-11-2015.

Corresponding Author:

Dr. Naresh Dawat,

Flat: 602, Sixth Floor, Eiffel Tower,

CHS, Sector 29, Nerul East,

Navi Mumbai-400707,

Maharashtra.

E-mail: naresh5949@gmail.com

DOI:10.14260/jemds/2015/2313.
The facial nerve plane is the most widely accepted landmark for division of the facial plane. Superficial lobe, which makes up about $80 \%$ of the volume of the parotid gland lies above the facial nerve and the part of tissue lying below the facial nerve is referred to as the deep lobe of the parotid. The extent of the surgery is dependent on the size and site of the tumor. In case of tumors located in the superficial lobe, the deep surgical margin is determined by the plane of the branches of the facial nerve. Parotid malignancies are very rarely multifocal and are very unlikely to metastasize to the deep lobe. Every effort should be made to preserve the facial nerve and its branches. The risk of damage to the facial nerve during surgical procedures of the parotid gland revealed the importance of knowledge of detailed anatomy of this region. ${ }^{5}$

CASE REPORT: A 50 year old female residing in rural areas of India, presented with a slow growing swelling in the left parotid region since 32 years. The swelling which initially began as a small lemon-sized mass had eventually increased to $8 \times 5 \mathrm{cms}$, with no sudden increase in size. It was not associated with pain or fever.

There was no difficulty in chewing or salivation and no medical intervention was sought for 32 years. A thorough history was taken and no comorbidities were present. On examination, a firm and non-tender swelling of $8 \times 5 \mathrm{cms}$ was palpable in the left parotid region, pushing the left ear lobule forward. It had bosselated surface with smooth margins. The swelling was fixed to underlying structure but skin pinchability was present.

There were no palpable cervical lymph nodes. An ultrasonography performed revealed a diffuse enlargement of the superficial lobe of the left parotid gland measuring $8.1 \times 4.4 \mathrm{cms}$. Fat planes were well maintained and no destruction of surrounding structures were noted. There was no obvious ductal dilatation noted. FNAC performed was suggestive of pleomorphic adenoma. MRI scan of the left parotid region was done preoperatively which also revealed pleomorphic adenoma. The patient was prepared for surgery 
and intraoperatively the tumour was seen bifurcating the gland into superficial and deep lobes.

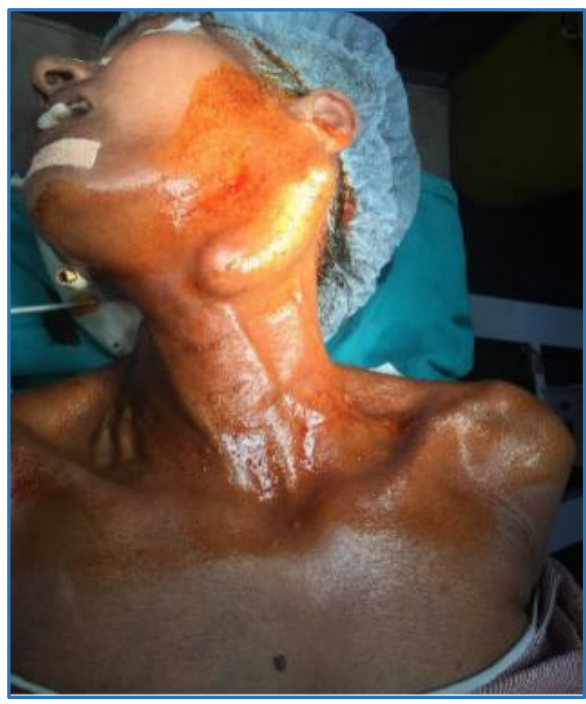

Fig. 1: Swelling over left parotid region

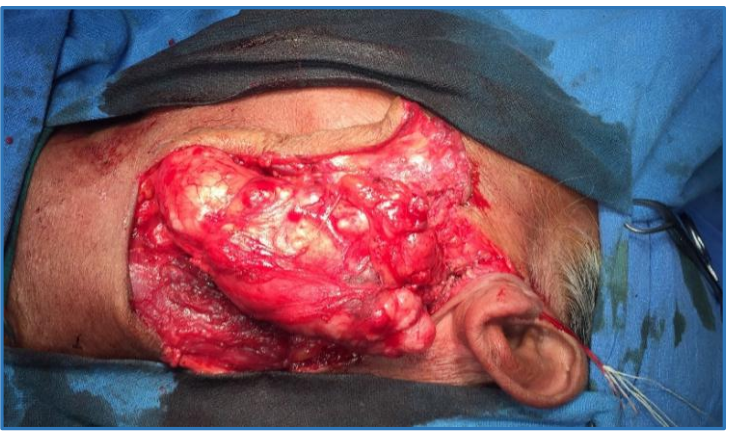

Fig. 2: Tumor involving the superficial lobe of the gland

The facial nerve and its five divisions in the parotid gland could be easily identified and preserved. The specimen was then sent for histopathology which confirmed the diagnosis of pleomorphic adenoma. A surgical drain was placed postoperatively and was removed when minimal collection was noted after four days. The patient was followed up over a period of 6 months and no intraoperative or postoperative complications were noted.

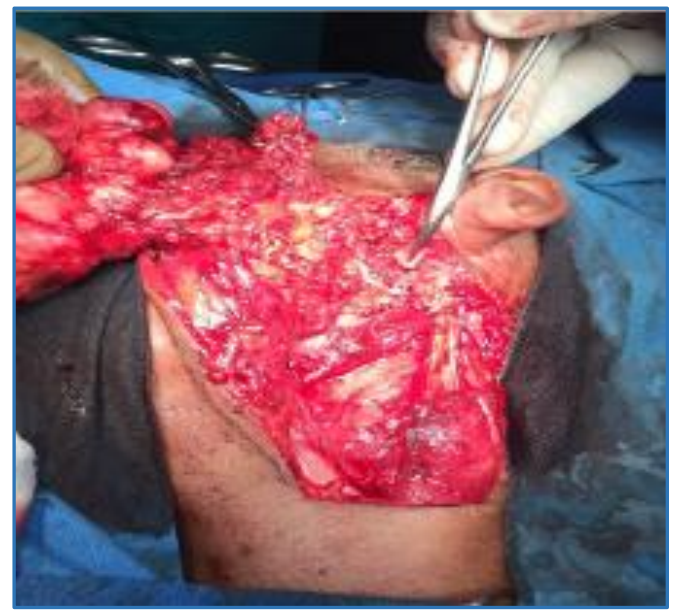

Fig. 3: Tragal pointer

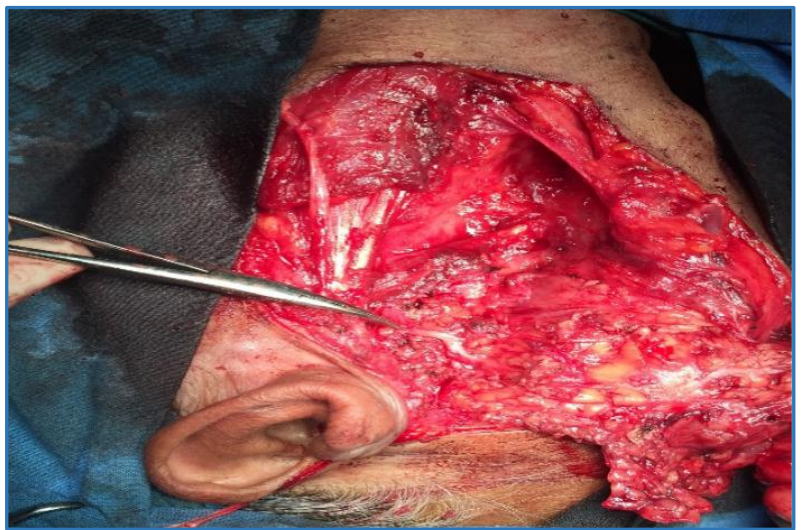

Fig. 4: Facial nerve and its branches identified and preserved after removing the superficial lobe

DISCUSSION: Anatomically, the parotid gland is a single unit; however, the need for surgical division arose taking into account the importance of preservation of facial nerve, frequent recurrence of benign tumours following parotidectomy and increased postoperative complications. Gregoire (1912) describe the gland as two lobes where facial nerve lying superficially to the larger lobe and deep to the smaller lobe. ${ }^{6}$ McWhorter (1917) said that the two lobes of parotid gland were connected by isthmus of the gland tissue from which the two main division of nerve passed between them. ${ }^{7}$

They were cervico-facial and temporo-facial divisions. Rouviere \& Cordier (1934) concluded that both Gregoire and McWhorter were partly correct, because after seeing two foetal parotid gland, they said that deep lobe was formed of tissue coming over the nerve as well as passing between the two main divisons. ${ }^{8}$

In the beginning, benign tumours of the parotid gland were treated with enucleation, i.e., removal of the tumour leaving behind the capsule. Seeing that the recurrence rates were high with this surgery, the techniques of surgical resection were modified to remove the gland in toto and to preserve the facial nerve. Today, superficial parotidectomy with facial nerve preservation is the method of choice in treating benign lesions of the parotid gland. ${ }^{9}$

The standard treatment of pleomorphic adenomas in the parotid gland is a surgical procedure. However, adverse outcomes of the surgical procedures are common. The recurrence rate of pleomorphic adenoma after surgery has been reported to be $1 \%-45 \% .^{10}$ The wide range of the rate depends on the type of surgical procedures. The recurrence rate after tumor enucleation has been reported to be $20 \%$ to $45 \% .{ }^{10}$

The high rate of recurrence is considered to be associated with positive margins consisting of incomplete tumor capsules. Other suggested causes of recurrence of pleomorphic adenoma are the perforating pseudopodia of the tumor, capsule rupture by the surgical procedure, and the proximity of the tumor to facial nerves. ${ }^{11}$ In our case, the pleomorphic adenoma was spread in such a fashion that it led to the distinct demarcation both superficial and deep lobes of the parotid gland with identification of facial nerve, thereby facilitating complete resection during surgery. 
CONCLUSION: It is of paramount important of identification of anatomic landmarks where all the surgeons are liable to know when performing parotidectomy either superficial, deep or total removal of the parotid gland. ${ }^{12}$

While preservation of the facial nerve poses as the major challenge to surgeons, the clear outline in our case due to the unusual spread of the tumour helped in preventing any major handling of the nerve and easy prevention of any iatrogenic injury.

\section{REFERENCES:}

1. Eveson JW, CAwson RA. Salivary gland tumors. A review of 2410 cases with particular reference to histological types, site, age, and sex distribution. Journal of Pathology 1985; 146: 51-8.

2. Spiro RH. Salivary neoplasms: Overview of a 35-year experience with 2,807 patients. Head and Neck surgery 1986; 8: 177-84.

3. Speight PM, Barrett AW. Salivary gland tumors. Oral diseases 2002; 8: 229-40.

4. Renehan A, Gleave EN, Hancock BD et al., long term follow up of over 1000 patients with salivary gland tumors treated in a single centre. British journal of Surgery 1996; 83: 1750-4.

5. Laing MR, McKerrow WS. Intraparotid anatomy of the facial nerve and retromandibular vein. Br J Surg. 1988; 75: $310-312$.
6. Gregoire R. Lenerf facial et al., parotide. J. Anat, Paris. 1912;48, 437-447.

7. McWhorter G.L. The relations of the superficial and deep lobes of the parotid gland to the ducts and to the facial nerve. Anat, Rec. 1917; 12, 149-154.

8. Rouviere H, Cordier G. Sur le developpement de la glande parotide et les connexions qui existent entre les deux lobes de cette glande. Ann. Anat. PATH. MEDCHIR.193.

9. Hoffman H, Funk G, Endres D: Evaluation and surgical treatment of tumors of the salivary glands. In Comprehensive Management of Head and Neck Tumors. Volume 2. 2nd edition. Edited by Thawley SE, Panje W, Batsakis L, Robert J. Philadelphia: W. B. Saunders Company; 1999::1147-1177.

10. Witt, R.L. (2002) The Significance of the Margin in Parotid Surgery for Pleomorphic Adenoma. Laryngoscope,112,2141-

2154.http://dx.doi.org/10.1097/00005537200212000-00004.

11. Lam, K.H., Wei, W.I., Ho, H.C. and Ho, C.M. (1990) Whole Organ Sectioning of Mixed Parotid Tumors. The American journal of Surgery, 160, 377-381. http://dx.doi.org/10.1016/S0002-9610(05)80547-1.

12. Brasil J.C., Jamieson E.B. (1981): Cunningham's textbook of Anatomy, 8 Edition. p.993. London: Oxford. University Press. 